\title{
Testicular germ cell tumours - a model for a new approach to treatment of adult solid tumours
}

\author{
R.T.D. Oliver \\ The London and St Bartholomew's Hospital Colleges and the Institute of Urology, London, UK.
}

\section{Introduction}

Cure of patients with disseminated cancer using medical as opposed to surgical or radiotherapeutic treatments has been a reality, albeit for a tiny minority, since children with leukaemia were treated with aminopterin (Farber et al., 1948) and patients with Hodgkin's disease were treated with mustine (Dameshek et al., 1949). Although the cure rate with the single agent treatment was less than $20 \%$ it was this durable disease control which separated these two diseases from most of the other cancers when these and other cytotoxic drugs were subsequently tested. This criterion of having a durable cure rate with single agent chemotherapy is common to all the tumours in which combination chemotherapy was subsequently shown to produce more than $50 \%$ cure (Simone, 1979; Simone et al., 1982; Bagshawe, 1976; Devita, 1981).

The most notable recent success in this respect has been the results of treatment of malignant germ cell tumours of the testicle. It is the purpose of this paper to review the results of this treatment and consider its significance in the broader context of the more general problem of the failure to produce such results from use of chemotherapy in the majority of adult solid tumours.

\section{History of the development of chemotherapy in germ cell tumours of the testis}

Germ cell tumours have featured prominently in the history of cancer chemotherapy since the first report of the apparent cure of patients with terminal Stage 4 metastatic disease ( $\mathrm{Li}$ et al., 1960). The use of chemotherapy was encouraged by the exceptional results being achieved at that time in the treatment of choriocarcinoma in women. It was hoped that choriocarcinoma in men, a rare sub-type of teratoma, might respond similarly. Initially, combination treatment with methotrexate, actinomycin and chlorambucil was tested on the assumption that the more drugs

R.T.D. Oliver, M.D., F.R.C.P.

Correspondence: Department of Medical Oncology, The London Hospital, Whitechapel London, E1 2AD UK. given, the better the result. This did not prove to be the case and six years later, a review of the results from the same centre showed that equally good results were achieved using actinomycin D alone (Mackenzie, 1966). Subsequent follow-up of these patients for as long as 22 years showed that the $8 \%$ who remained disease-free beyond two years all became long-term survivors (R. Golbey, personal communication).

Several other drugs showed equivalent activity as single agents (Bruckner, 1959; Fitzharris et al., 1980; Wyatt and McAninch, 1967; Williams, 1977). However there followed ten frustrating years of testing different combinations (McElwain and Peckham, 1974) without any further improvement in the chance of either complete response or long term 'cure'. It was the pioneering work of Samuels in 1973 which produced the first break through the $10 \%$ survival barrier. He increased the dosage of vinblastine and bleomycin to double that used previously and then used the two drugs in combination. The long-term cure rate of $35 \%$ was substantially more than the $8 \%$ achieved with single agent chemotherapy (Samuels et al., 1976).

No sooner had these results been reported than the next new drug reported to be active as a single agent, cisplatinum (Higby et al., 1974), was added to produce a three-drug combination bleomycin, vinblastine, cisplatinum (BVP).

Since the demonstration that close to two-thirds of patients could be cured with BVP (Einhorn \& Donohue, 1977), there have been three reports from other centres adding cisplatinum to the multiple drug combination (in some cases involving 4 or more drugs) that they were using at the time and have achieved at least as good or possibly better results. However, it is difficult to compare precisely the four different regimens since each study uses slightly different criteria for defining types of patients treated and each group has demonstrated a $10-15 \%$ improvement in results in the 4 years since they first reported their results (Peckham et al., 1979; Einhorn and Williams, 1980; Newlands et al., 1980: Newlands et al., 1983; Peckham et al., 1983b, Vugrin et al., 1981; Vugrin et al., 1983) from an average of $55-60 \%$ up to $75-80 \%$. 
My own experience has mirrored this change with the 2 year survival increasing from $30-80 \%$ when the results of patients receiving BVP between 1978-80 are compared with those treated between 1980-82 (Figure 1). Most of this improvement has come from experience in using the regimens, particularly due to attention to the detail of administration of the treatment, experience and judgement in timing, and dosage adjustment to avoid deaths related to drug toxicity. In addition, more rational decisions on amount of treatment have been made possible by the judicious use of post-treatment surgical staging in patients whose tumour markers have returned to normal but residual metastases are detectable radiologically (Oliver $e t$ al., 1983).

This surgery often has to be very extensive and occasionally involve concurrent chest and abdominal operations and occasionally necessitate division of the vena cava and grafting of the aorta (Merrin et al., 1978; Rowland and Donohue, 1984). Though twothirds of the patients have no visible malignant tissue detectable, more than $90 \%$ of such patients survive without further chemotherapy. If additional chemotherapy is given to those with persistent malignancy about a half can be salvaged (Einhorn et al., 1981).

The results of treating metastatic teratoma with modern platinum-containing chemotherapy are dramatic but there is still a small percentage of drug resistant cases, mainly those with large volume metastases which have accumulated due to prolonged delay in diagnosis. The demonstration that etoposide (Fitzharris et al., 1980), could salvage a small percentage of

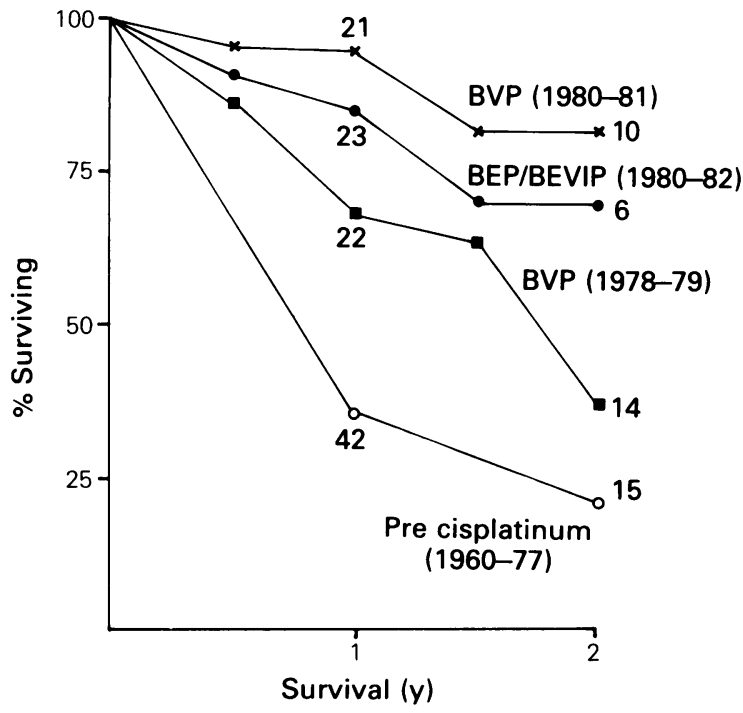

Figure 1 Actuarial survival of patients with metastatic teratoma according to chemotherapy treatment. BE-VIP = bleomycin, etoposide, vinblastine, cisplatinum. patients who have failed cisplatinum therapy has led to endeavours to incorporate this drug into combination regimens.

When this was attempted, there was considerable increase in toxicity (including treatment related deaths) without any clear cut increase in cure rate. With the demonstration by Peckham et al. (1983b) that removal of vinblastine from this four drug regimen did not decrease the initial response rate but did reduce the toxicity, even when compared to the BVP regimen, bleomycin, etoposide and cisplatinum (BEP) has become the standard regimen in this unit.

\section{Current controversies}

\section{Prognostic factors and the need for more than three drugs}

Two groups have developed multiple drug combination regimen using more than three drugs by incorporating cisplatinum into the regimen they were using at the time cisplatinum became available. Newlands $e t$ al. (1980) gave platinum, oncovin, methotrexate, bleomycin (POMB), alternating with actinomycin D, cyclophosphamide, etoposide (ACE), alternating with hydroxurea, vinblastine and chlorambucil while Vugrin (1981) used bleomycin, vinblastine, cytoxano actinomycin, platinum alternating with vinblastine and adriamycin. These authors reported their results after Einhorn and Donohue (1977) and showed slight $=$ ly better results at the expense of a much longer period of treatment and diminished proportion of patients who recovered fertility after treatment. As they became aware that the number of drugs was not as important as the quantity of cisplatinum their results improved in line with the results from the Einhorn regimens (Newlands et al., 1983; Oliver et al., 1984). There has been considerable debate whether the additional drugs and duration of treatment was necessary. Part of the uncertainty was due to the differing ways in which different authors assessed the extent of disease in their analysis of prognostic factors. In Newlands' series, tumour marker levels were of paramount importance over-riding tumour volume and site of metastases, while for Peckham et al. (1983) it was tumour volume and site, the poorest results seen in patients with brain and liver metastases. Until recently, the cure of patients presenting with brain metastases using POMB/ACE was the most convincing evidence that there might be some advantage for the multiple drug regimens over the shorter duration (3 months) BVP/BEP types of treatment.

The recent report of Lester $e t$ al. (1984) that patients who develop brain metastases before chemotherapy are curable with BVP and the recent results of a retrospective multivariate analysis of the results from 
Table I Prognostic factors for disease free survival of patients with malignant teratoma receiving platinum-containing chemotherapy

\begin{tabular}{|c|c|c|c|}
\hline & No of patients & $\%$ disease & ree survival $2 y$ \\
\hline Treatment prior to 1980 & 23 & $35 \%$ & \\
\hline Treatment $1980-82$ & 42 & $77 \%$ & $P=0.02$ \\
\hline Delay to first chemotherapy $<6$ months & 28 & $79 \%$ & \\
\hline$>6$ months & 37 & $51 \%$ & $P=0.04$ \\
\hline$\alpha \mathrm{FP}<500 \mathrm{KU} / 1$ and $\mathrm{HCG}<1000 \mathrm{IU} / 1$ & 34 & $71 \%$ & \\
\hline$\alpha \mathrm{FP}>500 \mathrm{KU} / 1$ and $\mathrm{HCG}>1000 \mathrm{IU} / 1$ & 32 & $47 \%$ & $P=0.02$ \\
\hline $\begin{array}{l}\text { Paraaortic mode }<2 \mathrm{~cm} \\
\text { and/or lung metastases }<2 \mathrm{~cm}\end{array}$ & 18 & $89 \%$ & \\
\hline $\begin{array}{l}\text { Paraaortic node } 2-5 \mathrm{~cm} \\
\pm \text { lung metastases }<2 \mathrm{~cm} \text { or } \\
\text { less than } 3 \text { in number }\end{array}$ & 12 & $58 \%$ & $P=0.04$ \\
\hline $\begin{array}{l}\text { Paraaortic node }>5 \mathrm{~cm} \text { and/or } \\
\text { lung metastases }>3 \text { in number } \\
\text { and at least } 1>2 \mathrm{~cm} \text { in diameter }\end{array}$ & 36 & $50 \%$ & \\
\hline
\end{tabular}

$\alpha \mathrm{FP}=\alpha$ fetoprotein $\quad \mathrm{HCG}=$ human chorionic gonadotrophin

6 centres in the UK (MRC Testicular Tumour Working Party Report, 1984), have somewhat diminished the certainty of Newland's arguments. In the MRC study, 485 patients treated with four main types of chemotherapy were reviewed. Though the data demonstrated the importance of both tumour volume and marker level, both of which were related to the duration of delay, there was no significant difference between the differing chemotherapy regimens but a major difference in respect of the year in which the patient was treated, the most recently treated cases i.e. those after 1982 having an eighty two per cent, two year survival. Similar results are demonstrable in the multivariate analysis of my own cases (Table I).

Though these results do not make a strong case for the use of methotrexate-containing combinations over the three drug regimens, the need for further improvement in survival is emphasized by the fact that in the MRC study only $47 \%$ of the patients in the worst prognostic group with both high markers and large volume disease survived whichever drug regimen was used. It is an interesting paradox that in all of the chemocurable tumours it is very difficult to prove that more than 3 or 4 drugs are of any benefit. Though the most convincing evidence comes from the Bonadonna

Table II Error rate of lymphography (Hermanek, 1976)

\begin{tabular}{|c|c|c|c|c|}
\hline & $n$ & \multicolumn{3}{|c|}{$\begin{array}{c}\text { Histopathological evidence } \\
\text { of metastases at lymph } \\
\text { node dissection }\end{array}$} \\
\hline $\begin{array}{l}\text { Lymphogram } \\
\text { positive }\end{array}$ & 314 & $\stackrel{+}{276}$ & $\overline{38}$ & $\begin{array}{c}\% \text { error } \\
12 \%\end{array}$ \\
\hline $\begin{array}{l}\text { Lymphogram } \\
\text { negative }\end{array}$ & 278 & 70 & 208 & $25 \%$ \\
\hline
\end{tabular}

$+=$ present; $-=$ absent study of MOPP versus MOPP/ABVD in patients with Hodgkin's disease (Santoro et al., 1980), the lack of confirmation of this study from other centres leaves the question still unresolved. Despite these provisos, the large number of drugs producing 5-10\% long term cure of patients with metastatic teratoma as a single agent suggests that further investigation of alternating combinations is worth pursuing in these patients with an extremely poor prognosis.

\section{The accuracy of radiological and tumour marker staging procedures and their relevance to the early diagnosis and management of Stage 1 and 2 tumours}

Over the last 30 years various radiological and biochemical staging procedures have been introduced into the management of germ cell tumours. All have had false positive and false negative readings which are important to take into consideration when managing these patients. In most instances it has been the use of retroperitoneal surgery which has enabled the accuracy of various procedures to be assessed. Table II shows the results of pathological correlation with lymphangiogram and Table III shows the correlation between pathological findings and computed

Table III Error rate of CT scan

\begin{tabular}{lccc}
\hline & $\begin{array}{c}\text { Histopathological evidence } \\
\text { of metastases at } \\
\text { lymph }\end{array}$ \\
& + & - & $\%$ node dissection \\
\hline CT scan positive & 67 & 7 & $9 \%$ \\
CT scan negative & 47 & 60 & $44 \%$ \\
\hline
\end{tabular}

$+=$ present; $-=$ absent . 
tomographic (CT) scan findings. Both procedures have considerably more false negative than false positive readings though when both procedures are done in parallel evidence of tumour is only demonstrated in an additional $5 \%$. Though the false negatives are more frequent they are usually corrected by repetition of the test. False positives are much more significant in that patients may then be given life threatening chemotherapy unnecessarily. In most situations where the need to treat is based solely on radiological investigation i.e. the tumour markers are negative, it is routine to repeat the staging procedures to show progression, or undertake a fine needle biopsy to establish that there is viable malignancy.

Though tumour markers $\alpha$ feto protein $(\alpha \mathrm{FP})$ and $\beta$ subunit of human choriogonadotrophic hormone ( $\beta \mathrm{HCG})$ are well defined markers of germ cell tumours, the occurrence of raised levels in other tumours and the occurrence of false positive $\alpha F P$ after hepatitis and false positive readings in some HCG assays due to cross-correlation with luteinizing hormone means that they cannot be relied upon absolutely. Though these false positives are usually easy to spot, recent experience of treating three patients in whom $\alpha F P$ plateaued in the region of $50-150 \mathrm{u} / \mathrm{ml}$ after POMB/ACE chemotherapy as has been reported by Coppack et al. (1983) has made one wary of placing absolute faith in a single measure of disease activity. The demonstration that in children methotrexate is hepatoxic may provide an explanation of the false positives in patients on POMB/ACE chemotherapy.

\section{Surgical versus radiotherapy in management of retroperitoneal lymph node involvement}

Since Boden and Gibb (1951) reviewed the early postwar results of radiotherapy in the UK and Patton and Mallis (1959) those following retroperitoneal lymph node dissection in America, there has been a continuing debate in the literature over the relative merits of the two methods of treatment for teratoma, though on both sides of the Atlantic the use of radiotherapy became standard practice for Stage 1 and 2 seminoma.

Most of the data which fuelled the arguments on the relative merits of retroperitoneal surgery or radiotherapy has come from single institutions making comparisons with historical controls. These have been reviewed by Oliver et al. (1984). If allowance is made for the era when the patient was treated and thus the selection process occurring because of the increasing sophistication of radiological, pathological and biochemical staging procedures there is no difference in the results for the two techniques. Because of changes in staging procedures over the past 30 years there has been a major change in the frequency of the various subtypes and their subsequent survival (Figures 2 and 3) (Oliver et al., 1983). Because of these observations,

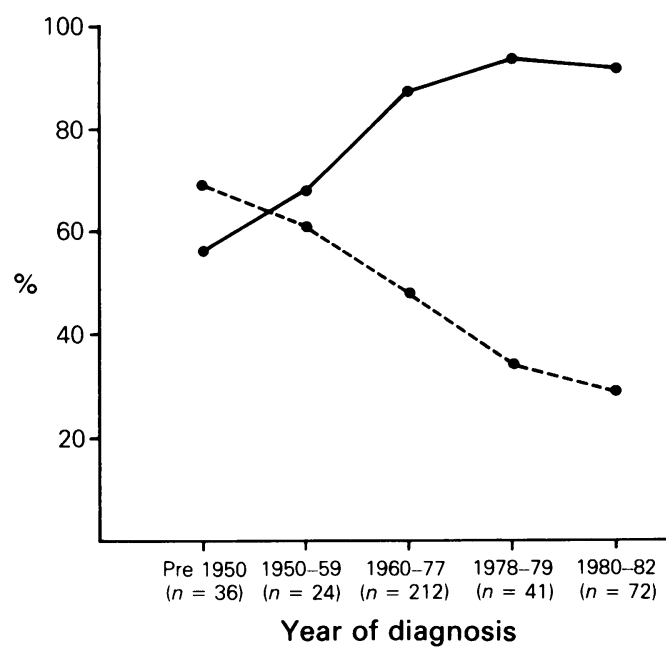

Figure 2 Seminoma as a proportional of all germ cell tumours. (-) \% of seminomas achieving longterm cure. ( - - - ) seminomas as \% of all treated germ cell tumours.

and bone marrow toxicity arising from using chemotherapy after radiotherapy, and because of the psychological aspects of ejaculatory impotence whicl occurs in patients after lymph node dissection there has been a need to re-examine the survival following orchidectomy alone of patients found to be without any metastases detectable by modern methods. In our series, 5 of 21 patients with malignant teratoma followed for an average of 18 months have relapsed

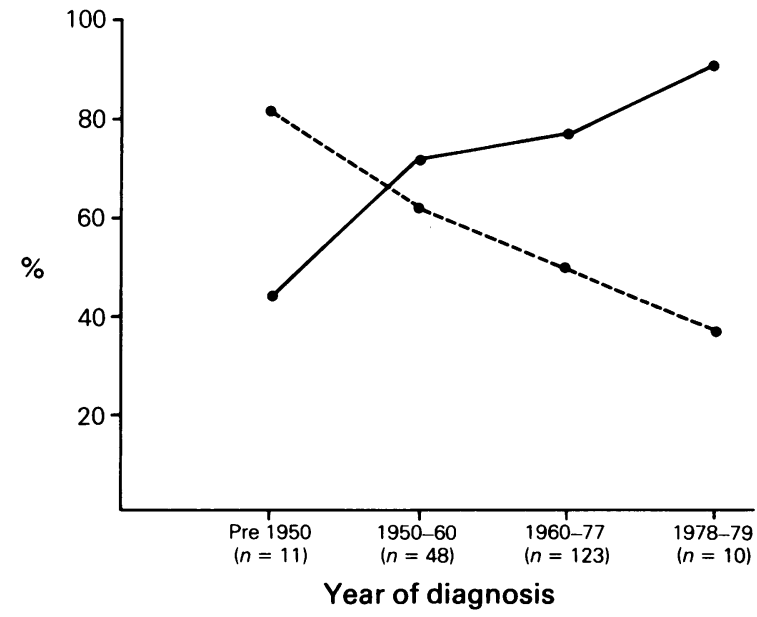

Figure 3 Stage 1 malignant teratoma as a proportion of all patients with malignant teratoma (O-O) longterm cure (\%); (O- - - ) \% of all non-seminoma. 
(Oliver et al., 1983), and one of eleven patients with seminoma (Oliver et al., 1984). All have been salvaged with combination radiotherapy, (follow up 3, 4, 5, 6, 11 and 27 months).

This series complements the much larger series of teratoma patients reported by Peckham et al. (1983) whose current relapse rate is $19 \%$ in a series of 53 cases and Reed et al. (1978) whose relapse rate is $22 \%$ in a series of 46 cases. As yet there have been no other series of patients with Stage 1 seminoma followed by surveillance.

Though these results establish that it is safe to consider surveillance as an alternative to prophylactic radiotherapy or retroperitoneal lymph node dissection in the management of patients, there are several disadvantages to this approach. It puts severe restrictions on the mobility of the patient for the period of intense follow-up. Though at present all relapses have occurred within 12 months of diagnosis, the recent report of late relapses, up to and beyond 5 years after chemotherapy for metastatic disease means that for Stage 1 patients the follow-up must be for longer than was originally suggested. Undoubtedly, some patients will default from follow-up because they do not understand the seriousness of their condition. The second disadvantage to this approach is that because of the need to keep close contact with these patients, surveillance is a very labour intensive method of managing them. The final disadvantage is that the seeming simplicity of the method may lead the individual surgeon who does the orchidectomy to follow his one or two patients a year without getting adequate experience in all the problems which occur in managing these patients and reducing the referral to specialist centres. Because of these problems the ultimate aim of surveillance studies must be to define patients with the highest risk of relapse who would benefit from prophylactic chemotherapy.

\section{Treatment options for Stage 2 metastatic teratoma}

Chemotherapy will cure close to $100 \%$ of patients with small volume metastases (MRC Testicular Tumour Working Party Report, 1984), but because of the toxicity, is a less preferred option. Though surgery or radiotherapy have a $50 \%$ relapse rate, they also have a $100 \%$ cure rate as the patients who relapse are salvageable by chemotherapy. However, the marrow and gut toxicity of chemotherapy given to patients who relapse shortly after radiotherapy is leading radiotherapists to use chemotherapy first.

Whether it is necessary to give as much chemotherapy to Stage II patients as to Stage IV patients is not clear. Preliminary results from an as yet unpublished randomized trial have shown that two adjuvant courses given to patients with Stage II disease after retroperitoneal lymph node dissection totally preven- ted the $50 \%$ relapse that normally occurs in patients who do not receive adjuvant treatment (Einhorn, personal communication).

It is clear from these results that there are three equally effective ways of treating patients with small volume and medium volume Stage II tumours: chemotherapy, surgery and salvage chemotherapy, or radiotherapy and salvage chemotherapy. Today, the decision as to the most appropriate treatment for Stage II is difficult and is a question of balancing the pros and cons of the different modalities of treatment as far as the patient is concerned: a young recently married patient without children might prefer to tolerate the extra toxicity of 3 months' chemotherapy compared with the short-term discomfort of surgery with the greater than $50 \%$ chance of loss of ejaculation; in contrast, an older patient with grown-up family who lives far from a treatment centre or has an overseas job may prefer surgery and two courses of adjuvant chemotherapy, rather than risk a $50 \%$ chance of having to have 3 months' chemotherapy at a later date, which would be more toxic in the case of the older patient.

For the future, given the high cure rate of these cases it is possible that the development of less toxic chemotherapy either by elimination or reduction of dosage of the most toxic drug in the combination will lead to chemotheraphy becoming the routine. Currently, trials underway through the EORTC and MRC testis tumour groups aim to investigate this point.

\section{Management of patients with seminoma of the testicle}

Until recently, radiotherapy has been the principal modality of treatment for all stages of seminoma. Stage 1 seminoma today is as selected a group of patients as Stage 1 teratoma compared to when prophylactic radiotherapy became standard (Figure 2). With the cure rate being higher than $95 \%$ and the treatment associated with minimal side effects, it will be more difficult to justify discontinuing radiotherapy in these patients. However, the observation of Fossa (1984) that prophylactic radiotherapy can affect the patient's sperm counts does provide a justification for considering re-investigation of the survival of Stage 1 seminoma using surveillance.

There are two additional factors which have made it possible to consider patients with Stage 1 seminoma for surveillance. First, the demonstration that placental alkaline phosphatase is a marker of metastatic seminoma and can be used to monitor patients (Lange et al., 1982). Secondly, the demonstration of the exquisite sensitivity of patients with metastatic seminoma to chemotherapy. The initial cure rate of previously untreated patients by single agent cisplatinum $(79 \%)$ is as good as that achieved with the intense combination regimes (Oliver et al., 1984), 
which became standard because of the success of such regimes in the management of patients with metastatic malignant teratoma.

\section{Fertility problems before and after treatment}

Approximately $20 \%$ of patients presenting with testicular tumour have total absence of sperm in their ejaculate and on average the sperm count in the remaining patients is less than in a normal population. This suggests that damage to the contralateral testis has preceded the development of the tumour. The incidence of this is higher in patients who have had a history of cryptorchidism. However, this is not an explanation for all of the cases. Mumps orchitis is one condition that can induce azoospermia and has also been associated with the development of testicular tumours (Beard et al., 1977), arousing increased interest in this virus.

Despite the low sperm count of these patients it is surprising that the sperm count recovers to pretreatment levels in the majority of patients after cytotoxic chemotherapy (Figure 4) provided it is not prolonged beyond 3 months. To date there have been no serious fetal defects in any of the children conceived by the patients' wives.

Similar experience was noted in the era when radiotherapy was the routine treatment. Retroperitoneal lymph node dissection in contrast, though not affecting libido, was associated with a high incidence of loss of ejaculation due to interference with the nerves in the sacrococcygeal plexus. More recently, with better knowledge of the anatomy of these nerves, more limited operations have been developed for

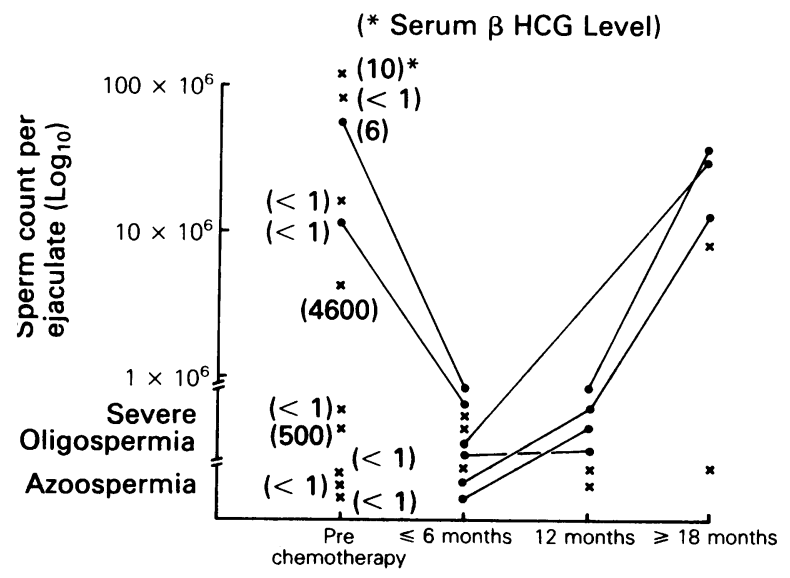

Figure 4 Sperm count in patients with malignant teratoma before and after chemotherapy.
Stage 1 patients avoiding these nerves and leading to recovery of ejaculation in $50 \%$ of patients. This is rarely possible in patients having the excessive dissections necessary for advanced Stage 2 disease (Fraley \& Lange, 1984).

\section{Early diagnosis}

There is still widespread ignorance even amongst the medical profession that today close to $90 \%$ of all testicular tumours are curable (within the limits of the eight years since the introduction of platinum-containing chemotherapy regimes). There is equal ignorance that delay is an important determinant of both the chance of a long term cure and of equal importance given the toxicity of combination chemotherapy, a determinant of the amount of treatment that will be necessary.

Today $80 \%$ of patients with a Stage 1 malignant teratoma survive disease-free after orchidectomy alone (Oliver et al., 1984; Peckham et al., 1983a; Reed et al., 1983). In a review of cases treated in this unit, the average delay from first symptom to diagnosis was 2 months in those patients on surveillance who had remained disease free after follow up for one year. For those patients who subsequently died of drug-resistant disease the average delay was 7 months (Table IV) Looked at from another perspective, $95 \%$ of those with less than one month's delay in diagnosis had no clinically obvious metastases at presentation while $50 \%$ of those with more than 6 months delay had clinically identifiable metastases (Table V). The need for wider dissemination of modern ideas about the curability of germ cell tumours and the need for early diagnosis is an important consequence of these observations, though from the point of view of the average practitioner the most important consequence should be to aim to get any patient with a suspicious lesion in his testicle on to an operating list within one week of presentation.

\section{Relevance of the chemoresponsiveness of germ cell tumours to the treatment of other adult malignancies}

Very little work has been done to investigate the exquisite chemo- and radiosensitivity of germ cell tumours. Though limited work has been done on in vitro drug sensitivity testing, what has been done (Von Hoff, 1980) does not suggest that they are very much more sensitive in vitro than any other adult tumour. If this can be confirmed by more detailed results it may be that other mechanisms than direct drug sensitivity are involved such as differences in DNA repair mechanisms of immunogenicity of the tumour cells.

One possible explanation of why germ cell tumours 
Table IV Impact of delay in diagnosis on occurrence of metastases and response to chemotherapy of testicular teratoma

\begin{tabular}{lcc}
\hline & $\begin{array}{c}\text { Median } \\
\text { duration } \\
\text { of delay } \\
\text { (months) }\end{array}$ & $\begin{array}{c}12 \text { months } \\
\text { delay }\end{array}$ \\
\hline $\begin{array}{l}\text { Patients without metastases at presentation and now disease } \\
\text { free on surveillance }\end{array}$ & $0 \%$ \\
$\begin{array}{l}\text { Patients found to have metastases; currently NED 12 months } \\
\text { post chemotheraphy }\end{array}$ & 17 & 2 \\
$\begin{array}{l}\text { Patients found to have metastases and now dead from } \\
\text { drug-resistant tumour }\end{array}$ & 36 & 4 \\
\hline
\end{tabular}

NED $=$ No evidence of disease

are so much more sensitive to drugs than other adult tumours may be that they are in fact an example of a retarded form of a neonatal or paediatric tumour. From birth until puberty, the stem cells from which they arise are in a resting state because of the lack of hormone drive, and it is only when they are activated at puberty that the become susceptible. Support for this idea comes from a recent report that prenatal factors may be involved in their aetiology (Pike et al., 1983), as has been seen from other paediatric tumours.

These observations raise doubts as to whether germ cell tumour chemotherapy has any relevance to the chemotherapy of the common adult solid tumour. However, there is some evidence that a minority of patients with the common adult tumours may show a similar degree of chemoresponsiveness. Because of the severe toxicity of the germ cell tumour chemotherapy regiments, particularly in the older patient, there have been few such studies.

Most have been in patients with widely metastatic poorly differentiated carcinomas. In my own series of 14 such cases, there have been 11 responses, 2 of whom had pathologically documented complete response. Recent results from a large series of such cases (Greco, 1984 ) have suggested that as many as $20 \%$ may have become long term survivors. Further exploration of this interesting observation is clearly indicated.

\section{Conclusion}

For most solid cancer in adults (and particularly breast cancer) the occurrence of late relapse up to 20 years after initial treatment makes most clinicians reluctant to use the word 'cure' when dealing with the disease. However, in testis cancer, even though it is clear that very occasionally a patient presenting initially with very advanced disease may develop late metastases (less than 1 per cent of total) and patients can develop tumours in the contralateral testis, it is permisssible to consider disease-free survival beyond 2 years as an important determinant of long-term survival. Given the young age of these patients and the fact that these drugs have been in use for less than 10 years, it will, nevertheless, be important that all centres involved in the treatment of such patients take special care to follow them up for life, not only to establish the cure rate but also to rule out the possibility of any late toxicity problems.

Despite this proviso it cannot be disputed that the last decade has witnessed a revolution in the treatment of germ-cell tumours of the testis. Part of this has been due to the developments that have occurred in radiological, biochemical and histopathological staging, which given the success of chemotherapy make it unnecessary to give prophylactic radiotherapy or retroperitoneal lymph node dissection to patients without metastases, the lower the chance of long-term cure. The demonstration of a direct relation between delay and extent of disease suggests that further improvement in survival of patients with metastatic disease will come from encouraging early recognition of testicular tumours by both patients and clinicians.

For the future, four priorities have been defined. First, to balance the discomforts and long-term sequelae of surgery and cytotoxic chemotherapy in patients with early metastasis to the retroperitoneum. Secondly, to discover less toxic regimens that can be used prophylactically in Stage 1 patients with a high risk of relapse. Thirdly to find better ways of defining when it is safe to stop chemotherapy in patients who

Table V Impact of delay after first symptoms on clinical stage at diagnosis of testis tumour

\begin{tabular}{llccc}
\hline & \multicolumn{2}{c}{ Seminomas } & \multicolumn{2}{c}{ Teratomas } \\
& $n$ & $\begin{array}{c}\text { Stage } 1 \\
\%\end{array}$ & $n$ & $\begin{array}{c}\text { Stage } 1 \\
\%\end{array}$ \\
\hline$<1$ month & 15 & 93 & 31 & 97 \\
$2-5$ months & 37 & 87 & 44 & 80 \\
$>6$ months & 41 & 90 & 25 & 60 \\
\hline
\end{tabular}


have necrotic tissue or mature teratoma remaining after successful treatment. Fourthly, to attempt to develop better methods to determine the minority of

\section{Acknowledgements}

Fig 1-3 reproduced by permission from British Journal of Urology

\section{References}

BAGSHAWE, K.D. (1976). Risk and prognostic factors in trophoblastic neoplasis. Cancer, 38, 1373.

BEARD, C.M., BENSON, R.C., KELALIS, P.P., ELVEBACK, L.R. \& KURLAND, L.T. (1977). The incidence and outcome of mumps orchitis in Rochester, Minnesota, 1935-1974, Mayo Clinic Proceedings, 52, 3.

BODEN, G. \& GIBB, R. (1951). Radiotherapy and testicular neoplasms. Lancet, ii, 1195.

BRUCKNER, W.J. (1959). Therapy of metastatic trophoblastic tumours of the testis. Journal of the Medical Sciences, $237,42$.

COPPACK, S., NEWLANDS, E.S., DENT, J., MITCHELL, H., GOKA, G. \& BAGSHAWE, K.D. (1983). Problems of interpretation of serum concentrations of alphafoetoprotein (AFP) in patients receiving cytotoxic chemotherapy for malignant germ cell tumours. British Journal of Cancer, 48, 335.

DAMESCHECK, W., WEISFUSE, L. \& STEIN, T. (1949). Nitrogen mustard therapy in Hodgkin's disease. Analysis of 50 consecutive cases. Blood, 4, 338 .

DE VITA, V.T., JR. (1981). Consequences of the chemotherapy of Hodgkin's disease. Cancer, 47, 1.

EINHORN, L.H. \& DONOHUE, J.P. (1977). Cis-diaminedichloroplatinum, vinblastine and bleomycin combination chemotherapy in disseminated testicular cancer. Annals of Internal Medicine, 87, 293.

EINHORN, L.H. \& WILLIAMS, S.D. (1980). Chemotherapy of disseminated testicular cancer: A random prospective study. Cancer, 46, 1339.

EINHORN, L.H., WILLIAMS, S.D., MANDELBAUM, I. \& DONOHUE, J.P. (1981). Surgical resection in disseminated testicular cancer following chemotherapeutic cytoreduction. Cancer, 48, 904.

FARBER, S., DIAMOND, L. \& MERCER, R. (1948). Temporary remission in acute leukemia in children produced by folic acid antagonist, 4-aminopteryl glutamic acid (Aminopterin). New England Journal of Medicine, 238, 787.

FITZHARRIS, B.M., KAYE, S., SAVERYMUTTU, S., NEWLANDS, E.S., BARRETT, A., PECKHAM, M.J. \& MCELWAIN, T.J. (1980). VP16-213 as a single agent in advanced testicular tumours. European Journal of Cancer, 16, 1193.

FOSSA, S. (1984). Proceedings of the International School of Urology and Nephrology, 5th course on Testicular Cancer 1983 (in press).

FRALEY, E.E. \& LANGE, P.H. (1984). Technical nuances of extended retroperitoneal dissection for low-stage nonseminomatous testicular germ-cell cancer. World Journal of Urology, 2, 43.

HERMANEK, P. (1977). Testicular cancer, histologic classification and staging, topography of lymph node metastases. Recent Results in Cancer, Research, 60, 202. adult solid cancer patients with poorly differentiated tumours who also show responses similar to germ-cell tumours when treated with these drugs.
HIGBY, D.J., WALLACE, H.J., ALBERT, D.J. \& HOLLAND, J.F. (1974). Diaminadichloroplatinum: A phase I study cancer, 33, 1219

LANGE, P.H., MILlAN, J.L., STIGBRAND, T., VESSELlA, R.L., RUOSLAHTI, E. \& FISHMAN, W.A. (1982). Placental alkaline phosphatase as a tumor marker for seminoma. Cancer Research, 42, 3244.

LESTER, S.G., MORPHIS, J.G., HORNBACK, N.B., WILLIAMS, S.D. \& EINHORN, L.H. (1984). Brain metastases and testicular tumours: need for aggressive therapy. Proceedings of the American Society for Clinical Oncology, 3, 152.

LI, M.C., WHITMORE, W.F., GOLBEY, R. \& GRABSTALD, H. (1960). Effects of combined drug therapy on metastatic cancer of the testis. Journal of the American Medical Association, 174, 145.

McELWAIN, T.J. \& PECKHAM, M.J. (1974). Combination chemotherapy in testicular tumours. Proceedings of the Royal Society of Medicine, 67, 297.

MacKENZIE, A.R. (1966). Chemotherapy of metastatic testi⿺ cancer results in 154 patients. Cancer, 19, 1369.

MERRIN, C., BECKLEY, S. \& TAKITA, H. (1978). Multimoda\$ treatment of advanced testicular tumour, Journal of Urology, 120, 79.

MRC Testicular Tumour Working Party Report on Prognostic Factors in Advanced Non-Seminomatous Testicular Germ-cell Tumours. (1984). Lancet (in press).

NEWLANDS, E.S., BEGENT, R.H.J., KAYE, S.B., RUSTIN, G.J.S. \& BAGSHAWE, K.D. (1980). Chemotherapy of advanced malignant teratomas: British Journal of Cancer, 42, 378.

NEWLANDS, E.S., BEGENT, R.H.J., RUSTIN, G.J.S., PARKER, D. \& BAGSHAWE, K.D. (1983). Further advances in the management of malignant teratomas of the testis and other sites. Lancet, i, 948.

OLIVER, R.T.D., HOPE-STONE, H.F. \& BLANDY, J.P. (1983). Justification of the use of surveillance in the management of Stage 1 germ cell tumours of the testis. British Journal of Urology, 55, 760.

OLIVER, R.T.D. (1984). Testis cancer, British Journal of Hospital Medicine, January, 23.

OLIVER, R.T.D., BLANDY, J.P., HENDRY, W.F., PRYOR, J.P., WILLIAM, J.P. \& HOPE-STONE, H.F. (1983). Evaluation of radiotherapy and/or surgico-pathological staging after chemotherapy in the management of metastatic germ cell tumours. British Journal of Urology, 55, 764.

OLIVER, R.T.D., BLANDY, J.P. \& HOPE-STONE, H.F. (1984). Possible new approaches to the management of seminoma of the testis. British Journal of Urology, 56, 729

PATTON, J.F. \& MALLIS, N. (1959). Tumours of the testis. Journal of Urology, 81, 457.

PECKHAM, M.J., BARRETT, A., HORWICH, A. \& HENDRY, 
W.F. (1983a). Orchidectomy alone for Stage 1 testicular non-seminima: A progress report. British Journal of Urology, 55, 754.

PECKHAM, M.J., BARRETT, A. \& LIEU, K.H. (1983b). The treatment of metastatic germ cell testicular tumours with bleomycin, etoposide and cis-platin (BEP). British Journal of Cancer, 47, 613.

PECKHAM, M.J., BARRETT, A., McELWAIN, T.J. \& HENDRY, W.F. (1979). Combined management of malignant teratoma of the testis. Lancet, i, 267.

PIKE, M.C., DEPUE, R.H. \& HENDERSON, B.E. (1983). Oestrogen exposure during gestation and risk of testicular cancer. JNCI vol 71: pp. 1151 - 1155 (1983).

REED, G., JOHNSON, J., WILKINSON, P.M.\& EDDLESTEN, B. (1978). Prospective study of follow-up alone in Stage 1 teratoma of the testis. British Medical Journal, 87, 1503.

ROWLAND, G.R. \& DONOHUE, J.P. (1984). Cytoreductive surgery in testicular cancer. World Journal of Urology, 2, 48.

SAMUELS, M.L., LANZOTTI, V.J., HOLOYE, P.Y., BOYLE, E.L., SMITH, T.L. \& JOHNSON, D.E. (1976). Combination chemotherapy in germinal cell tumours. Cancer treatment Review, 3, 185.

SANTORO, A., BONADONNA, G. \& BONFANTE, V. (1980). Non-cross resistant regimens (MOPP and ABVD versus
MOPP alone) in Stage IV Hodgkin's disease. Proceedings of the American Society of Clinical Oncology, 16, 470.

SIMONE, J.V. (1979). Childhood leukemia as a model for cancer research: The Richard and Hinda Rosenthal foundation award lecture. Cancer Research, 39, 4301.

SIMONE, J.V., CASSADY, R.J. \& FILLER, R.M. (1982). Cancers of Childhood. In: Principles and Practice of Oncology, By: DeVita, V.T., Hellman, S., \& Rosenberg, S. A. Lippincott: Philadelphia.

VON HOFF, D.D. (1980). Clinical correlation of drug sensitivity in tumour stem cell assay; Proceedings of the American Society for Clinical Oncology, 21, 134.

VUGRIN, D., CVITKOVIC, E., WITTES, R.E. \& GOLBEY, R.B. (1981). VAB-4 combination chemotherapy in the treatment of metastatic testis tumours. Cancer 47, 833.

VUGRIN, D., WHITMORE, W.E. JR. \& GOLBEY, R.B. (1983). VAB-6 combination of chemotherapy without maintenance in treatment of disseminated cancer of the testis. Cancer, 51, 211.

WILLIAMS, C. (1977). Current dilemmas in the management of non-seminomatous germ cell tumours of the testis, Cancer Treatment Review, 4, 1.

WYATT, J.K. \& McANINCH, L.N. (1967). A chemotherapeutic approach to advanced testicular carcinoma. Canadian Journal of Surgery, 10, 421. 